\title{
Heavy Hydrogen and Heavy Water
}

$\mathrm{T}$ HE mass of the hydrogen atom, 1.00778 土 0.00015 , found by Aston with the massspectrograph, appeared to be in very satisfactory agreement with the chemical atomic weight, which is one of the most accurately determined (A. Scott ; Morley; Burt and Edgar). The discovery of the isotopes of oxygen, howover, made it clear that the values found by the mass-spectrograph were referred to the oxygen isotope $\mathrm{O}^{16}=16 \cdot 000$, whilst the chemical values were referred to the isotopic mixture $\mathrm{O}=\mathbf{1 6} \cdot 000$. The factor for the conversion of mass-spectrograph values to chemical values now generally accepted is based on the spectroscopic abundance ratio $\mathrm{O}^{16}: \mathrm{O}^{18}$ determined by .Mecke and Child ${ }^{1}$, and Aston's value on the chemical standard then becomes 1.00756 , which is certainly too low for the mass of the ordinary hydrogen atom.

Birge and Menzel $^{2}$ thereupon suggested that ordinary hydrogen contains a small amount of a heavier isotope, $\mathrm{H}^{2}$, of mass approximately double that of the lighter isotope, $\mathrm{H}^{\mathbf{1}}$, and that only the latter was noticed in Aston's measurements. In order to reconcile the latter with the chemical atomic weights, an abundance ratio $\mathrm{H}^{1} / \mathrm{H}^{2}$ of 4,500 in ordinary hydrogen is required. It may be said at once that, although the presence of the isotope $\mathrm{H}^{2}$ has been firmly established, it is present in very much smaller amount than this calculation suggests, say $\mathrm{H}^{1} / \mathrm{H}^{2}=30,000 \pm 20$ per cent ${ }^{3}$, and that the discrepancy between the mass-spectrograph and chemical values of the atomic weight still remains.

The presence of $\mathrm{H}^{2}$ in ordinary hydrogen was proved by Urey, Brickwedde and Murphy ${ }^{4}$, who examined the optical spectrum of samples from the residues of the evaporation of liquid hydrogen and found faint lines at the calculated positions for $\mathrm{H}^{2}$. The broad $\mathrm{H}^{2} \alpha$ doublet was resolved and the separation agreed with theory. The relative abundance ratio $\mathrm{H}^{1} / \mathrm{H}^{2}$ was calculated as 4,000 , which would explain very nicely the discrepancy just noted, but this result has since been shown to be incorrect. The isotope effect was also found in the Lyman series of hydrogen produced by a discharge in the vapour of 'heavy' water $^{5}$.

The presence of $\mathrm{H}^{2}$ was then demonstrated by means of the mass-spectrograph by Bainbridge ${ }^{6}$, who found the atomic mass $2 \cdot 01351 \pm 0.00006$ relative to $\mathrm{He}$ and $2 \cdot 01351 \pm 0.00018$ relative to $\mathrm{O}^{16}$, the equivalent packing fraction being 0.675 per cent. Mass-spectrograph evidence for $\mathrm{H}^{2}$ was also found by Kallmann and Lazareff ${ }^{7}$. Grace ${ }^{8}$ calculated theoretically the atomic weight $\mathrm{H}^{2}=2 \cdot 0113 \pm 0 \cdot 0012$.

The nucleus of $\mathrm{H}^{2}$, at first regarded as an association of two protons and one electron $\left(p_{2} e\right)$, might clearly play an important part in the composition of nuclear structure ${ }^{9}$. The discovery of the neutron and the positron (positive electron) has given alternative possible structures for the nucleus of $\mathrm{H}^{2}$ (which has been called the deuteron or deuton); for example, it may consist of two neutrons, conceived as primary uncharged particles of mass 1, and one positron. The proton, on this scheme, loses its supposed fundamental character as a constituent of atomic. nuclei, and becomes an association of a neutron and a positron $^{10}$.

A partial separation of the isotopes $\mathbf{H}^{1}$ and $\mathrm{H}^{2}$ was achieved by E. W. Washburn and Urey ${ }^{11}$, who examined the water from commercial electrolytic cells which had been operating two to three years. An examination of the optical spectrum of the hydrogen from this water showed an increase in the abundance of $\mathrm{H}^{2}$. The oxygen from this water was combined with nitrogen and the nitric oxide spectrum examined. This showed that there was a decrease in the $\mathrm{O}^{18}$ isotope concentration of about 8 per cent. The ratio $\mathrm{H}^{1} / \mathrm{H}^{2}$ in natural terrestrial hydrogen might depend on the particular sample examined, since there might have been some separation in the method used in preparing the hydrogen. It has also been found that $\mathrm{H}^{2}$ tends to 'clean up' in a discharge tube ${ }^{12}$, so that estimates of relative abundance based on optical emission spectra may well be erroneous. A marked increase in specific gravity, freezing point and boiling point, and a decrease in refractive index of water which had undergone prolonged electrolysis, were found ${ }^{13}$.

Lewis and Macdonald started with twenty litres of water from an old electrolytic cell, which was half-normal in alkali, and electrolysed it between nickel electrodes with $250 \mathrm{amp}$. until the volume was reduced by ninety per cent. One tenth was neutralised with carbon dioxide and the rest distilled. The two portions were recom. bined. The process was repeated until the volume had been reduced to half a cubic centimetre, the electrolysis being conducted below $35^{\circ}$, and preferably near $0^{\circ}$, in order to minimise loss by evaporation, and the current being reduced as the volume of liquid diminished. A difference in cathodic polarisation of 0.04 volt between $\mathrm{H}^{1}$ and $\mathrm{H}^{2}$ is reported. There was no accumulation of the heavy isotope of oxygen, $\mathrm{O}^{18}$. As a final result, water of specific gravity 1.073 , estimated to contain 65.7 per cent of the hydrogen as $\mathrm{H}^{2}$, was obtained. The relative losses of $\mathrm{H}^{1}$ and $\mathrm{H}^{2}$ were five to one, and a further reduction to one quarter of the final volume on electrolysis, it was supposed; would give water containing 99 per cent of its hydrogen as $\mathbf{H}^{2}$. The estimate of the concentration of $\mathbf{H}^{2}$ in ordinary water as 1 in 6,500 given in this paper is too high.

Newell and Ficklen ${ }^{14}$ examined the specific gravity of water from chromium plating baths which had been operating for periods up to three 
years: specimens from nine baths had specific gravities varying from $1 \cdot 00002$ to $1 \cdot 00064$.

When water is distilled through a fractionating column, a large separation of the isotopes of hydrogen and oxygen can be effected, especially if the distillation is carried out under reduced pressure $^{15}$. A 20-ft. column was used and in two modes of operation: (i) the ordinary isotopic composition was maintained at the foot of the still, when a stationary state was reached after two days, the water at the head showing a diminished density of 60 parts in a million; and (ii) the ordinary isotopic composition was maintained at the head of the column and samples were taken daily from the foot, when the density rose by 70-80 parts per million above that of ordinary water. Although the heavy water has an appreciably lower vapour pressure than common water, the differences are rather illusory in connexion with separation by distillation, since there is an exchange of $\mathrm{H}^{1}$ and $\mathrm{H}^{2}$ atoms among the water molecules, and an appropriate calculation shows that it is not the vapour pressure itself but its square root which is proportional to the atomic fraction. Distillation under reduced pressure should be more effective. A large still in operation for two months has shown a steady increase in density of the water at the bottom of the still $^{16}$.

The method used by G. N. Lewis and Macdonald ${ }^{17}$ in separating the hydrogen and oxygen of a given sample of water, and thus determining how much of the increase in density is due to $\mathrm{H}^{2}$ and how much to $\mathrm{O}^{18}$, depends on passing the steam over heated iron. This is cumbrous, and Lewis ${ }^{18}$ has devised a method depending upon the exchange of isotopes in aqueous solution, as in the reaction with ammonia on water:

$$
\mathrm{H}^{1} \mathrm{H}^{2} \mathrm{O}+\mathrm{NH}^{1} \mathrm{H}^{1} \mathrm{H}^{1}=\mathrm{H}^{1} \mathrm{H}^{1} \mathrm{O}+\mathrm{NH}^{1} \mathrm{H}^{1} \mathrm{H}^{2} .
$$

Ammonia in water may be regarded as forming ammonium hydroxide, $\mathrm{NH}_{\mathbf{4}} \mathrm{OH}$, and again dehydrating, the two changes proceeding with great velocity, and as the fourth hydrogen of the ammonium group is exactly like the others, each hydrogen has an equal chance of being lost on dehydration. A rapid interchange of such hydrogen isotope as is present will give a nearly random distribution between $\mathrm{NH}_{3}$ and $\mathrm{H}_{2} \mathrm{O}$. One mol of water at $0^{\circ}$ absorbs nearly one mol of $\mathrm{NH}_{3}$, and since ammonia has three hydrogen atoms, more than half the $\mathrm{H}^{2}$ in the system will escape when the ammonia is pumped off. A sample from the still with an excess density over ordinary water of 0.000182 was saturated with ammonia at $0^{\circ}$ and the ammonia pumped off at room temperature. After six repetitions of the process, the water had an excess density of 0.000085 , so that at least $0 \cdot 000097$ of the original density excess was due to $\mathrm{H}^{2}$. Another experiment consisted in using sulphur dioxide instead of ammonia :

$$
\mathrm{H}_{2} \mathrm{O}^{18}+\mathrm{SO}^{16} \mathrm{O}^{16}=\mathrm{H}_{2} \mathrm{O}^{16}+\mathrm{SO}^{16} \mathrm{O}^{18},
$$

when the density excess was reduced to $0 \cdot 000109$, so that 0.000073 at least of the original excess was due to $\mathrm{O}^{18}$. In this crude experiment, $0 \cdot 000170$ of the 0.000182 is accounted for.

In precision work the isotopic composition of the ammonia will have to be found, particularly if it has been prepared from electrolytic hydrogen, and precautions must be taken against any large loss of water by evaporation.

It is interesting to note that $\mathrm{Holmboe}^{19}$ has reported that electrolytic hydrogen is more active in ammonia synthesis than other equally pure hydrogen obtained by reduction of steam by iron: the velocity of reaction was $10-40$ per cent greater with electrolytic hydrogen.

An alternative method of separation of $\mathrm{H}^{2}$ from electrolytic hydrogen is suggested by experiments by Bleakney, Gould and Taylor ${ }^{20}$, who report that an enrichment in $\mathrm{H}^{1} \mathrm{H}^{2}$ occurs when the gas is progressively removed from charcoal on which it has been adsorbed, in agreement with some theoretical results of Eyring.

Practically pure 'heavy water', $\mathrm{H}_{2}^{2} \mathrm{O}$, was obtained by Lewis and Macdonald ${ }^{21}$, whose experiments on its physical properties were carried out with 0.12 e.c. of liquid in which the proportion of $\mathrm{H}^{1}$ isotope was probably not greater than 0.01 per cent. The freezing point was found to be $+3 \cdot 8^{\circ}$ and the boiling point $101 \cdot 42^{\circ}$. The vapour pressure curve was established and the following values for the ratio $p_{2} / p_{1}$, where $p_{1}$ is the vapour pressure of ordinary water and $p_{2}$ that of heavy water, were found:

$\begin{array}{lllllllllll}t^{\circ} \mathrm{C} . & 20 & 30 & 40 & 50 & 60 & 70 & 80 & 90 & 100 & 110\end{array}$

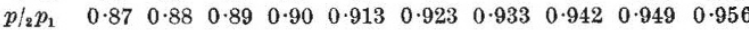

The usual calculation shows that the latent heat of evaporation is greater than that of ordinary water by $259 \pm 3$ or $4 \mathrm{gm}$. cal. per mol. The density at $25^{\circ}$ was found to be $1 \cdot 1056$ and the temperature of maximum density $+11 \cdot 6^{\circ}$. The values of $\mathrm{vol} . /\left(\mathrm{vol}\right.$. at $\left.4^{\circ}\right)$ were as follows :

$\begin{array}{ccccccccc}t^{\circ} \mathrm{C} . & 5 & 10 & 15 & 20 & 25 & 30 & 35 & 40 \\ V_{4}^{t} & 0.99987 & 0.99948 & 0.99958 & 1.00016 & 1.0011 & 1 \cdot 00243 & 1.00415 & 1.00605\end{array}$

In the various respects in which water is said to be an abnormal liquid, heavy water $\left(\mathrm{H}_{2}^{2} \mathrm{O}\right)$ seems to be more abnormal, but the difference between the two becomes smaller with rising temperature.

Several miscellaneous investigations on $\mathrm{H}^{2}$ and $\mathrm{H}_{2}^{2} \mathrm{O}$ have recently been reported. The nuclear $\operatorname{spin}^{22}$ of $\mathrm{H}^{2}$ is (by exclusion) probably $2 / 2$, or twice that of $\mathrm{H}^{1}$; the emission spectrum of hydrogen with 25 per cent $\mathrm{H}^{1} \mathrm{H}^{1}, 50$ per cent $\mathrm{H}^{1} \mathrm{H}^{2}$ and 25 per cent $\mathrm{H}^{2} \mathrm{H}^{2}$, and the electronic band spectrum due to neutral $\mathrm{OH}^{2}$, have been examined 22, 23 .

The mobility of the ions in $\mathrm{H}_{2}^{2} \mathrm{O}$ was examined ${ }^{24}$ by determining the conductivities of hydrogen and potassium chlorides in ordinary water and in nearly pure $\mathrm{H}^{2} \mathrm{O}$. A special pipette cell containing 0.25 c.c. of liquid, with bare platinum wire 
electrodes, was used. The amount of $\mathrm{H}_{2}^{2} \mathrm{O}$ in the electrolytic liquid was determined from the density, and the resistances were extrapolated from 97 per cent $\mathrm{H}_{2}^{2} \mathrm{O}$ to 100 per cent. The ratios of the equivalent conductancos in ordinary water and $\mathrm{H}_{3}^{2} \mathrm{O}$ were thus obtained. Results at five temperatures from $5^{\circ}$ to $18^{\circ}$ were found. It is assumed that the ratio of equivalent conductance to equivalent conductance at infinite dilution is the same for oach electrolyte in the two solvents and that the ratio of the mobilities of the $\mathrm{K}+$ and $\mathrm{Cl}-$ ions is the same in both solvents. The mobilitios at $18^{\circ}$ for $\mathrm{H}^{2+}, \mathrm{K}^{+}$and $\mathrm{Cl}-$ in pure $\mathrm{H}_{8}^{2} \mathrm{O}$ are then calculated as $213 \cdot 7,54 \cdot 5$ and $55 \cdot 3$, if the corresponding mobilities of $\mathrm{H}^{1+}, \mathrm{K}^{+}$and $\mathrm{Cl}^{-}$ are $315 \cdot 2,64.2$ and 65.2 . It thus appears that the ionic molilities in heavy water are distinctly smaller than in ordinary water. The values of the conductance ratios aro believed to be accurate to half per cent.

Irewis, even before he had succeoded in concentrating $\mathrm{H}^{2}$, had predicterl that $\mathrm{H}^{2} \mathrm{H}^{2} \mathrm{O}$ would not support lifo and would bo lethal to higher organisms. Ho then found oxperimentally $2 s$ that minute seods of tobacco (Nicotina tabacum var. purpurea) responded to this test. 'Twelve seeds wore placed in pairs in six similar glass tubes and to oach of three tubes 0.02 c.c. of ordinary distilled water and to each of the other three tubes 0.02 c.c. of pure $\mathrm{H}_{2}^{8} \mathrm{O}$ were added. The six tubes were hermetically sealed and placed in a thermostat at $25^{\circ}$. The threo pairs of soods in ordinary water bogan to sprout in two days, and at the end of a fortnight had formed well developed seedlings. The seeds in $\mathrm{H}_{2}^{2} \mathrm{O}$ showed macroscopically no devolopment: they have been put in ordinary water but the result is not yet reported. Six entirely similar tubos, oach containing two seeds, wero filled alternately with ordinary distilled water and with water in which half the hydrogen was $\mathrm{H}^{2}$. At the end of four days, all six seeds in ordinary water gavo woll-developed seedlings, whilst those in tho heavier water all showed about the samo degree of sprouting as occurs in ordinary wator in two days.

The toxic effect of ordinary distilled water is familiar ${ }^{26}$. A peculiar effect of thormal treatmont of water on its capacity for promoting tho develop. ment of cells of Spirogyra, reported by Illoyd and Barnes $^{26}$, was attributed to the difforent proportions of polymerised water molecules in froshly condensed steam and freshly melted ice. Ice ${ }^{27}$ has been regarded as $\left(\mathrm{H}_{2} \mathrm{O}\right)_{n}$, perhaps $\left(\mathrm{H}_{2} \mathrm{O}\right)_{3}$, liquid water as largely $\left(\mathrm{H}_{2} \mathrm{O}\right)_{2}$ with some $\left(\mathrm{H}_{2} \mathrm{O}\right)_{3}$ and $\mathrm{H}_{2} \mathrm{O}$, and dry steam as $\mathrm{H}_{2} \mathrm{O}$. At $20^{\circ}$, it has been ealculated, there is $31 \cdot 1$ per cent of liquid ice in liquid water, and freshly melted ice should contain much more $\left(\mathrm{H}_{2} \mathrm{O}\right)_{3}$ than freshly condensed steam, since the changes of polymerisation aro not rapid. In freshly melted ice, rich in trihydrol, the cells of Spirogyra developed normally, whilst freshly condensed steam, rich in dihydrol and monohydrol, killed the cells. Barnes and $\mathrm{Jahn}^{28}$ have since reported that Euglena develops much moro rapidly in water from freshly melted ico than in condensed steam.

Fvidence regarding the offect of thermal troatment on the physical properties of water is, however, conflicting. Wills and Boeker ${ }^{29}$ say that the diamagnetic suscoptibility is altered by such treatment, whilst Menzies ${ }^{30}$ found no alteration of vapour prossure, and La Mer and Miller ${ }^{31}$ no change of refractive index, by such treatment. The latest speculations on the constitution of liquid water ${ }^{38}$ postulate a tetrahedral co-ordination of water molecules (five $\mathrm{H}_{2} \mathrm{O}$ molecules in a group) in ice and two other forms in addition in liquid water.

Until 1894, ehomists had no suspicion that the atmosphore contained any constituents other than those recognised by Lavoisier a century previously, and it has requirod the lapse of a century and a half to establish the existence in water, which like air is one of the commonest materials available to chemists, of anything more than two supposod 'olements', hydrogen and oxygen, each of which is now known to consist of a mixture of at least two different kinds of atoms. The chemical proporties of the heavy hydrogen isotope are very probably difforent from those of ordinary hydrogon. A new organic chemistry, in which each of the compounds containing carbon (of which there are also at least two isotopes, $\mathrm{C}^{12}$ and $\mathrm{C}^{13}$ ) and hydrogen is duplicated by the synthesis of a 'heavy' partnerat present a mere nightmare-will in lapse of time no doubt becomo an accomplishod fact. The use of heavy waters in medical treatment still awaits investigation.

\footnotetext{
${ }_{1}^{1}$ Phys. Rev., 36, 330; 1930; compare Naude, Z. Phy8., 68, 362 ; 1931 .

Phys. Rev., 37, 1669 ; 1931.

'Bleakney, Phys. Rev., 41, 32 ; 1932

4 Phys. Rev., 40, 1; 1932.

b Ballardow and White, Phys. Rev., 43, 941; 1933

- Phy8. Rev., 41, 115; 1932.

2 Naturwissenschaften, $20,206,472,1932$; possible $\mathrm{H}^{3}$. Compare also Conrad, '/. I'hys., 75, 5(14, 1932, nentral $\mathrm{H}^{2}$ particles in canal rays. Lewis and Spedding, l'hy8. Rev., 48, 964, 1933, find no spectroseopic evidence of $\mathrm{H}^{3}$, to 1 part in $10^{6}$, in very nearly pure $\mathrm{H}_{2}^{2}$; relative fine structures of $\mathrm{H}^{1}$ and $\mathrm{H}^{2}$ are given.

J. Amer. Chem. Soc., 54, 2582; 1932.

- Harkins, J. Amer. Chem. Soc., 54, 1254 ; 1932.

10 Sexl, Natcke, 132, 174; 1933.

11 Proc. Nat. Acad. Sci., 18, 498; 1932.

$"$ G. N. Lewis and Spedding, Phys. Rev., 43, 964; 1933.

'Washburn, Smith and Fransien, J. Chem. Phys., 1, 288; 1933 ; G. N. Lewis and Macionald, ibid., 341 .

14 J. Amer. Chem. Soc., 55, 2167; 1933.

${ }^{16}$ G. N. I.ewis and Cornish, J. Amer. Chem. Soc., 55, 2616; 1933.

18 G. X. Lewis, ibid., 55, 3502; 1933.

$17 \mathrm{~J}$. Chem. Phys., 1, 341; 1933.

18 J. Amer. Chem. Soc., 55, 3502; 1933.

19 Pincass, "Die industrielle Merstellung von Wasserstoff", 53 ; 1933.

to Phys. Rev., 43, 497; 1933.

${ }^{21}$ J. Amer. Chem. Soc., 55, 3057; 1933. Nature, 132, 248; 1933.

22 Lewis and Ashley, Phys. Rev., 48, 837; 1933. Ashley, ibid., 770.

12 Chamberlain and Cutter, I'hy8. Rev., 43, 772; 1933.

24 Lewis and Doody, J. Amer. Chem. Soc., 55, 3504; 1933.

2s J. Amer. Chem. Soc., 55, 3503; 1933.

20 Iloyd and Barnes, Proc. Nat. Acad. Sci., 18, 426; 1932. Nature, 183,$691 ; 1932$.

27 Barnes, Proc, Rov. Soc., A, 12), 070; 1929.

so Pror. Nut. Aral. Sri., 19, 638; 1933.

"Phys. Rev., 42, 687; 1932.

30 P'roc. Nat. Acad. Sci., 18, 587 ; 1932.

31 Phys. Rev., 43, 207; 1933.

" Fowler and Bernal, J. Chem. I'hys., August 1933. T. Faraday
} Soc., 29, 1049; 1933. 